\title{
Profissão docente: Conflitos e contradições na construção de uma docência periférica
}

\author{
Teaching profession: Conflicts and contradictions in the construction of a peripheral document \\ Profesión docente: Conflictos y contradicciones em la construcción de la docencia periférica
}

Recebido: 10/08/2021 | Revisado: 15/08/2021 | Aceito: 17/08/2021 | Publicado: 20/08/2021

\author{
Claudia de Medeiros Lima \\ ORCID: https://orcid.org/0000-0002-9914-0585 \\ Instituto Federal de Educação, Ciência e Tecnologia da Bahia, Brasil \\ E-mail: clamed.lima@gmail.com \\ Thais Pio dos Santos \\ ORCID https://orcid.org/0000-0002-3427-1007 \\ Instituto Federal de Educação, Ciência e Tecnologia da Bahia, Brasil \\ E-mail: thaispio764@gmail.com
}

\begin{abstract}
Resumo
Este trabalho objetiva discutir sobre as perspectivas da constituição da docência em licenciandos da Matemática, diante do baixo prestígio social, da precarização profissional e das recentes mudanças na política educacional para a formação de professores, proposta pela BNCC. As análises que serão apresentadas resultam de pesquisa de abordagem qualitativa, realizada em uma instituição pública federal de educação superior, situada na região metropolitana de um estado do nordeste do país. Para produção de dados optamos pelos grupos focais, questionários e pela técnica de análise de conteúdo. Os resultados encontrados apontam para a necessidade de impedir o processo de periferização do magistério em curso e, pela urgência de construção de uma proposta de formação inicial de professores voltada para a realidade dos jovens estudantes trabalhadores.
\end{abstract}

Palavras-chave: Docência; Formação de professores; BNCC; Licenciatura em matemática; Ensino.

\begin{abstract}
This paper aims to discuss the perspectives of the Mathematics undergraduates in constitution of teaching, against the low social prestige, professional precariousness and recent changes in educational policy for teacher training, proposed by the BNCC. The reviews that will be presented result from a qualitative approach research, carried out in a federal public institution of higher education, located in the metropolitan region of a state in the country's northeast . For data production, we chose focus groups, questionnaires and the content analysis technique. The results found point the need to prevent the ongoing process of teaching peripheralization and the urgent need to build a proposal for initial teacher education focused on the reality of young working students.
\end{abstract}

Keywords: Teaching; Teacher training; BNCC; Mathematics degree; Teaching.

\begin{abstract}
Resumen
Este trabajo tiene como objetivo discutir las perspectivas de la constitución de la docencia en los estudiantes del grado en Matemáticas, dado el bajo prestigio social, la precariedad profesional y los recientes cambios en la política educativa para la formación del profesorado, propuestos por el BNCC. Los análisis que se presentarán son el resultado de una investigación de enfoque cualitativo, realizada en una institución pública federal de educación superior, ubicada en la región metropolitana de un estado del noreste del país. Para la producción de datos, optamos por grupos focales, cuestionarios y la técnica de análisis de contenido. Los resultados encontrados apuntan a la necesidad de prevenir el continuo proceso de periferizacion de la docencia y, ante la urgente necesidad de construir una propuesta de formación inicial docente centrada en la realidad de los jóvenes estudiantes trabajadores.
\end{abstract}

Palabras clave: Docencia; Formación de professores; BNCC; Grado en Matemáticas; Enseñanza.

\section{Introdução}

Algumas considerações que antecedem esta proposta de investigação soariam familiares mesmo ao leigo em teorias sobre a educação, porquanto a depreciação e pouco reconhecimento da docência há algum tempo fazem parte da subjetividade coletiva.

Mesmo entre pessoas de diferentes estratos sociais é comum ouvirmos afirmações semelhantes acerca da baixa remuneração dos professores e sobre as precárias condições de trabalho, apesar de ser considerada uma profissão fundamental para sociedade. 
A escolha do magistério como profissão está diretamente ligada, então, à esta construção social "Tal reconhecimento e escolha estão hoje comprometidos em função da representação social da profissão, fortemente marcada por um sentimento de inferioridade, mediocridade e incapacidade". (Diniz-Pereira, 2011, p.47). Segundo o autor, essa questão tem refletido na baixa preferência dos jovens pela docência.

Podemos acrescentar, que além do declínio social da docência, a alta evasão nas licenciaturas, agravadas pelas baixas expectativas financeiras e dificuldades dos estudantes em manterem o próprio sustento durante a graduação. Sobre este dilema inicial origina-se o problema de investigação aqui proposto. Diante da profissão que se atribui determinada importância social, mas ainda assim se sabe desvalorizada e desprestigiada, como os licenciandos em matemática compreendem a docência?

Consideramos fundamentalmente válida toda investigação que se proponha esclarecer a compreensão dos futuros professores acerca da profissão. Assim como, avaliamos que as análises aqui realizadas possam contribuir significativamente com as produções científicas que transversalizam a formação e o exercício do magistério, em busca da valorização e fortalecimento da docência no país.

É importante destacarmos que este trabalho é resultado de pesquisa qualitativa desenvolvida em programa de Iniciação Científica em uma instituição pública federal localizada na região metropolitana do estado da Bahia. Para produção dos dados foram utilizados questionários e desenvolvidos grupos focais com estudantes da Licenciatura em Matemática, cujos resultados seguiram o enfoque da análise de conteúdo. Quanto ao traçado dos caminhos para a investigação, procuramos entender os motivos reais que levaram os estudantes a optar pela licenciatura. Também investigamos sobre as perspectivas dos estudantes para o futuro exercício profissional diante do panorama político educacional que se apresenta, bem como, sobre suas concepções acerca da docência antes e depois do contato com a graduação.

O reconhecimento da docência se torna um desafio, especialmente, quando fazemos uma reflexão sobre os problemas que há muito circundam o magistério brasileiro. De acordo com Tardif (2002) e Libâneo, Oliveira e Toschi (2012) é preciso destacar o contexto na qual a docência está inserida, atrelando os saberes do magistério a dada origem social.

Nesta mesma ótica, alguns teóricos incluem em suas análises a consideração acerca da opção pelas licenciaturas diretamente relacionada à origem social dos estudantes. "A imagem que a sociedade nos passa do magistério como uma ocupação fácil [...] vem colar com a autoimagem de despreparo que foram acumulando os adolescentes e jovens dos setores populares". (Arroyo 2013, p.127). Há, nesta abordagem uma construção do imaginário social sobre o magistério como profissão fácil, que requer do sujeito mais atitudes e comportamentos do que especialização técnica. Questão essa que tem influenciado na escolha pela docência como algo possível para os jovens trabalhadores, sobretudo ao considerarmos a necessidade de subsistência e ascensão econômica mais acelerada.

Além dos aspectos já apontados, ressaltamos o déficit histórico do país em relação à formação de professores ${ }^{1}$. Não podemos desconsiderar, inclusive, as modificações recentes na LDB 9.394/1996, viabilizadas pela Lei 13.415/2017 e pela Resolução CNE/CP 02/2019 e 01/2020 que trazem alterações significativas e de impacto negativo para formação e exercício docente. Existem, portanto, evidências significativas para a afirmação de que a formação de professores nunca ocupou a devida relevância no cenário educacional brasileiro, favorecendo ao magistério um status de profissão periférica.

São inúmeros textos científicos que abordam a desvalorização profissional e o baixo reconhecimento social da docência. A maioria deles aponta para a existência de uma crise do magistério que vem sendo construída ao longo de muitos anos e que tem se revelado motivo de preocupação para o processo de valorização da profissão. Associamos a isto, o precário

\footnotetext{
${ }^{1}$ É importante informar que, este trabalho ocupa-se, prioritariamente, com a formação inicial de professores por se tratar de uma investigação sobre a percepção de licenciandos, contudo, reconhecemos que a formação de professores compreende outros saberes.
} 
incentivo público para programas de incentivo a formação de professores e a tentativa de patrulhamento da prática docente, gerando um cenário de aprofundamento de crise.

\section{Metodologia}

Esta é uma pesquisa de abordagem qualitativa que, segundo Ludke e André (2013), favorece uma aproximação maior entre o pesquisador e o seu objeto de pesquisa, além de compreendermos que o problema investigado carece de familiarização e consideração das peculiaridades da comunidade local. "As narrativas agora precisam ser limitadas em termos locais, temporais e situacionais. No que diz respeito à pluralização dos estilos de vida e de padrões de interpretação na sociedade moderna e pós-moderna". (Flick, 2009, p.21) Apesar de ser uma abordagem qualitativa, não desprezamos os números para discutir o objeto.

A investigação surge a partir de inquietações dos pesquisadores acerca da desvalorização da docência e da constatação sobre o baixo índice de formandos no curso de Licenciatura em matemática de uma instituição pública federal da Bahia, lócus onde se desenvolveu as investigações. Oportunamente desenvolvemos a investigação a partir do Programa Institucional de Bolsas de Iniciação Científica (PIBIC), por conseguinte, valorizando a pesquisa no âmbito da formação de professores, tendo sido aprovada pelo Comitê de Ética e Pesquisa institucional, sob parecer nº 3.980.718.

Para fundamentação teórica principal, optamos pelas produções teóricas de Diniz-Pereira (2011); Veiga, Araújo e Kapuziniak (2017); Libâneo, Oliveira e Toschi (2012), em discursos que abordam sobre questões histórico-políticas que colaboraram para a crise do magistério. Arroyo (2013); Tardif; Lessard (2014). Gatti (2019) que contribuíram para a discussão sobre a construção do ofício docente. Ludke e André (2013); Gatti (2012); Bardin (2011) e Flick (2009) para os aspectos metodológicos. A fonte documental alicerçou os aspectos referentes ao aparato legal sobre formação de professores.

A pesquisa foi realizada com dez estudantes da Licenciatura em Matemática, obedecendo o critério de acessibilidade. O convite foi realizado para estudantes do segundo semestre e para estudantes em situação de conclusão de curso. Foi enviado email pessoal e chamada em grupo de whatsappp dos estudantes, convidando-os para participação da investigação. Todos os licenciandos que consentiram participar, compuseram os dois grupos de investigação. Destacamos a dificuldade em reunir os grupos, dada a coincidência do período de realização da fase empírica com o início da pandemia de COVID-19.

Para atender à problemática sobre a descoberta do sentido que os licenciandos imprimiam à docência no atual panorama educacional, decidimos pelo desenvolvimento de grupos focais (GF). Para Gatti, os grupos focais permitem maior interação entre os participantes, fluidez nas discussões e multiplicidade de pontos de vista "A pesquisa com grupos focais, além de ajudar na obtenção de perspectivas diferentes sobre uma mesma questão, permite também a compreensão de ideias partilhadas por pessoas no dia a dia e dos modos pelos quais os indivíduos são influenciados pelos outros.” (GATTI, 2012, p.11)

Baseado nessas considerações, elaboramos um roteiro semiestruturado com dez questões norteadoras, que contemplaram os temas: Aspectos envolvidos na escolha e permanência na Licenciatura em matemática; desinteresse dos jovens pelas licenciaturas; valorização do magistério; cenário político-educacional para formação e exercício docente; Saberes da docência aprendidos na graduação; política de formação de professores; percepções acerca da profissão docente antes e depois de entrar no curso de Licenciatura em Matemática.

Como já sinalizado, foram organizados dois grupos, em um GF trabalhamos com quatro estudantes, que cursaram pelo menos oito semestres e, no outro GF, trabalhamos com seis estudantes, que cursaram pelo menos dois semestres do curso. A escolha por distintos grupos, calouros e prováveis concluintes, visou garantir maior representatividade na pesquisa. 
Ainda na produção de dados, utilizamos de levantamento bibliográfico, levantamento documental e aplicação de questionário. Este último objetivou identificar o perfil dos estudantes da licenciatura que participaram da pesquisa e foi enviado aos estudantes por email, juntamente com o Termo de Livre Consentimento Esclarecido (TCLE). Todos os participantes concordaram em participar da pesquisa e responderam ao questionário, consentindo, inclusive, com os registros realizados através de gravação e anotações escritas. Todas as informações foram posteriormente transcritas e analisadas. É importante lembrar que se adotou nome de cores para representar e garantir o sigilo dos entrevistados.

As análises dos dados coletados foram fundamentadas nas técnicas de análise de conteúdo apresentada por Bardin (1977), mais especificamente, a análise temática frequencial. Adotada neste trabalho por reconhecermos o caráter polissêmico presente nas falas dos entrevistados. A análise interpretativa buscou conhecer os sentidos empregados durante o processo investigativo. Foi necessário, todavia, adotar uma interpretação que fugisse do excesso de subjetividade dos pesquisadores, antes seguisse os processos de validação científica.

Enquanto esforço de interpretação, a análise de conteúdo oscila entre os dois polos do rigor da objetividade e ela fecundidade da subjetividade. Absolve e cauciona o investigador por esta atração pelo escondido, o latente, o nãoaparente, o potencial de inédito (do não-dito), retido por qualquer mensagem. (Bardin, 1995, p.9)

Para alcançar os resultados apresentados aqui, segundo o método instituído por Bardin (2011), dividimos as análises dos dados em três fases: Pré-análise, exploração do material, tratamento dos resultados e interpretações.

Na pré-análise, em posse das transcrições, anotações realizadas durante os grupos focais e respostas dos questionários, realizamos, individualmente, leituras flutuantes. Esse processo foi realizado algumas vezes, a fim de garantir a exaustividade, representatividade, homogeneidade e pertinência na etapa, permitindo maior aprofundamento no problema de investigação. Logo após, foram realizadas sessões de diálogo entre os pesquisadores acerca dessas leituras. Esse processo de edição foi bastante cuidadoso para que não houvesse descontextualização dos achados, além de buscar manter a coerência com os objetivos de pesquisa.

A exploração do material, organizado em quadros, ocorreu a partir da seleção de palavras ou temas repetidos ao longo dos grupos focais. A codificação ocorreu através das unidades de registro e contexto, seleção de regras de contagem e escolha de categorias temáticas. Inicialmente, levantamos 19 indicadores, em seguida foi aplicada a regra de enumeração, frequência simples e diferenciação dos dados produzidos nos dois grupos investigados, veteranos e calouros. Posteriormente, realizamos uma associação dos 19 indicadores com os objetivos da pesquisa, promovendo nova reorganização em 7 subcategorias.

Para finalizar a preparação do material para as interpretações e inferências, realizamos novo reagrupamento, adotando os critérios de exclusão mútua, homogeneidade, pertinência, objetividade e fidelidade e produtividade, que culminou no estabelecimento de duas categorias finais de análise: Escolhas e desafios dos estudantes na Licenciatura em Matemática e Constituição da profissão docente entre tensões e contradições.

Nesta última etapa, priorizamos os dados mais significativos e com maior frequência de ocorrência entre os entrevistados. As inferências e interpretações surgiram das análises reflexivas e críticas dos pesquisadores em articulação com os objetivos da pesquisa e com as bases teóricas e metodológicas utilizadas na investigação.

\section{Resultados e Discussão}

Este tópico apresentará o tratamento dos resultados da pesquisa de acordo com as categorias finais das análises: Escolhas e desafios dos estudantes na Licenciatura em Matemática e Constituição da docência periférica. A primeira categoria atenderá ao objetivo de compreensão acerca da opção dos jovens estudantes pela licenciatura, associada aos dados do 
perfil levantado e a segunda categoria estará ancorada sobre as perspectivas para a profissão docente, na relação com o panorama político educacional e sobre a concepção de docência, antes e depois do contato com o curso de licenciatura.

\section{Escolhas e desafios dos estudantes na licenciatura em Matemática}

Quanto ao perfil dos estudantes da Licenciatura em Matemática, evidenciamos em quase sua totalidade, uma juventude trabalhadora, cuja renda familiar não ultrapassa 3 salários mínimos. São estudantes oriundos do ensino médio regular de escolas públicas. Apenas um deles não tem nenhuma ocupação profissional no momento, enquanto mais da metade dos entrevistados exerce atividades laborais com carga horária superior a 40 horas semanais.

Conforme as discussões de Arroyo (2013), Diniz-Pereira (2011), Gatti (2019), apesar de nos últimos anos ter havido aumento da presença dos jovens das classes populares no nível superior, ainda existe uma distinção entre os cursos para os quais estes são selecionados. As licenciaturas se tornaram cursos de representatividade para a população periférica. Nesse sentido, Gatti (2019) destaca haver uma segregação por curso nas universidades, assertiva evidenciada no levantamento do perfil dos estudantes participantes desta investigação.

É importante, contudo, ressaltar que o acesso desses jovens ao nível superior resulta de políticas públicas na área de educação, entre estas, as políticas de cotas e o aumento das vagas em nível superior. No entanto, é preciso levar em consideração a realidade vivenciada pelos jovens estudantes, que enfrentam inúmeros desafios para conciliar trabalho e estudos.

Eu pensei em desistir do curso, mas desistir não porque eu quisesse, era devido a circunstâncias que eu estava na época do início de 2015 para 2016, mas trocar de curso não. Eram [questões] pessoais, trabalho, família e religião, estava muito difícil para mim. (Rosa, 2020)

A desistência apontada por Rosa (2020), surgiu na fala de quase todos os entrevistados. Os estudantes afirmaram ter muitas dificuldades em conciliar horários de trabalho e horários de estudo. Somam-se a isso questões de ordem familiar e os deslocamentos diários realizados, muitos deles deslocam-se entre municípios distintos todos os dias. Sabemos que estudar e trabalhar é um desafio grande, mas quando se tem uma carga horária de trabalho superior a 40 horas esse desafio torna-se ainda maior, pois a vida acadêmica não se resume à sala de aula ou pelo menos não deveria. Qual o tempo que estes jovens teriam disponível para organizar uma rotina de estudos?

Pautando a necessidade de uma política sólida de formação de professores, Arroyo parte em defesa da importância do investimento na formação inicial de qualidade, salientando, todavia, que existem muitas dificuldades para os estudantes participarem de práticas extracurriculares, por exemplo. A maior parte dos licenciandos precisa conciliar a vida acadêmica com outras dinâmicas cotidianas. Essa é uma característica comum entre a juventude nas licenciaturas, fato que desafia a qualidade da formação e o exercício profissional desses futuros professores.

Sabemos por experiência de trabalho em escolas normais e em cursos de pedagogia como é difícil reunir os e as aprendizes de mestre em atividades extracurriculares, em atividades culturais, em debates, em pesquisas e até em mobilizações políticas. Não há tempo. A escola é um lugar de passagem, o trabalho, a família, são prioritários. (Arroyo 2013, p.130).

Quando solicitados a dialogarem sobre a escolha pelo curso de graduação, mais da metade dos estudantes relatou que a opção pela Licenciatura em Matemática estava ligada à comodidade de estudar e morar/trabalhar no mesmo município e pela possibilidade de empregabilidade futura. Sobre essa condição socioeconômica como definidora da escolha pelo curso, o estudante responde: 
[...] em 2016 eu trabalhava no comércio, eu era vendedora e eu não queria aquilo pelo resto da vida, não ter uma ajuda financeira dos meus pais, sou de família humilde, então eu vi no [nome da instituição] e no curso uma oportunidade de ter uma profissão, de me especializar na área, ser uma professora da educação básica ou não, depende se eu continuar estudando. Então para mim sim é uma questão socioeconômica. (Bege, 2020)

A escolha pelas licenciaturas, segundo Gatti (2019), está definida segundo os marcadores sociais e associada à condição de menor prestígio do magistério. Para os licenciandos, o magistério é uma oportunidade possível, uma forma de se obter uma profissão rápida e capaz de conciliá-la com as demais atividades de rotina pessoal, que talvez não fosse possível se estivessem em um curso considerado "mais complexo". Diniz-Pereira aponta esses desafios como limites para escolha profissional, tornando a docência uma alternativa mais viável. Vale lembrar, no entanto, que a evasão é um fantasma que ronda as licenciaturas. Muitos jovens não conseguem lidar com a rotina pesada de estudos e trabalho e, acabam desistindo.

A dificuldade de os alunos manterem o seu sustento durante a graduação, a baixa expectativa de renda em relação à futura profissão e o declínio do status social da docência fizeram que os cursos de licenciatura, tanto em instituições públicas como privadas, convivessem com altíssimas taxas de evasão. (Diniz - Pereira, 2011).

Ainda nessa perspectiva, Arroyo (2013) afirma que o processo de escolha da profissão considera aspectos que não se limitam apenas ao desejo dos estudantes de optar por determinada profissão, mas o que está ao alcance de se realizar "Não escolhemos a profissão que queremos, mas a possível. Essa condição está presente na socialização de toda nossa vida, sobretudo de nossa infância e juventude, na socialização das imagens profissionais e das posições que projetamos como possíveis". (Arroyo, 2013, p.126).

Vai ao encontro da afirmação do autor as análises dos questionários aplicados, onde é possível identificar que os estudantes entrevistados não têm vivências familiares que proporcionem maior contato com a universidade. Apenas um estudante tem pais/responsáveis com nível superior completo, ambos são professores. O que se pode inferir que o contato com o magistério durante a infância/juventude foi, talvez, uma das poucas socializações de imagem profissional desses estudantes com carreiras ligadas à uma universidade. Os alunos afirmaram que a escolha pela Licenciatura em Matemática remonta a identificação com a profissão à infância.

Sobre esse processo de identificação com o magistério, surge um dado relevante. Para os alunos veteranos, a necessidade de identificação com a matemática e com a docência é condição indispensável para escolha e permanência no curso. Enquanto no grupo dos calouros as respostas equilibram-se entre a necessidade de identificação com o magistério e com a área da matemática. Esse aspecto pode estar indicando a percepção dos estudantes veteranos sobre a alta evasão no curso. Eles sabem que o acesso ao nível superior pode estar mais facilitado, mas avaliam que a permanência e a conclusão demandam dedicação e identificação com a área/curso.

Também ligada a essa questão da identificação com a matemática, os alunos dialogaram acerca da complexidade das disciplinas do curso e apontaram para a fragilidade da formação matemática durante a educação básica. Essa condição surge na fala dos entrevistados, apesar de somente 3 alunos indicarem enfrentamento de dificuldades atuais com os conteúdos dos componentes curriculares. Os estudantes avaliam ainda, que a baixa identificação com a matemática ou disciplinas que envolvem cálculos, pode estar associada a deficiência dessa formação na educação básica.

A literatura utilizada coaduna com a realidade apresentada nesta investigação. As licenciaturas no país estão voltadas para os jovens trabalhadores, que escolhem a profissão dentro das suas possibilidades socioeconômicas. Esses jovens possuem carga extenuante de trabalho e enfrentam desafios cotidianos para conciliá-lo com os estudos. Podemos inferir a partir disso, que os futuros professores de matemática têm rotina de estudos comprometida, questão ainda mais acentuada ao consideramos 
que eles relatam trazerem, da educação básica, grandes dificuldades em cálculos. Esta situação sugere uma equação, cujo resultado, possivelmente, não trará benefícios para a docência.

Chama atenção, durante os grupos focais, que em nenhum momento os licenciandos reivindicaram o direito de ser somente estudantes para se dedicar exclusivamente aos estudos, como tantos outros jovens de classe média o são. Suas queixas se limitam aos horários das disciplinas que acontecem no turno vespertino, obrigando-os a aguardar nova oferta no noturno. Situação que pode agravar ainda mais o andamento do curso, principalmente se o componente curricular for pré-requisito para outro.

As discussões realizadas apontam para a periferização docente iniciada já no processo de escolha da profissão e continua com a precarização durante o processo de formação. É válido pontuar que os licenciandos se auto responsabilizam pela continuidade/desistência do curso, apesar de identificarem que trazem da educação básica, alta deficiência em matemática. Para quase todos os estudantes, a educação básica cursada foi avaliada como regular. Outrossim, afirmam que têm que se esforçar muito, individualmente, porque a matemática do nível superior é bem mais complexa e exige deles conhecimentos prévios que não possuem.

\section{Constituição da docência periférica}

Nesta categoria indicamos os resultados que evidenciam a construção do magistério sobre antigos conflitos. Para Charlot (2013), o professor se constitui entre "tensões e contradições", entre estas, situa-se a figura de um profissional exigido pelos padrões de qualidade e produtividade, dentro da lógica neoliberal e, controversamente, exigido pelo desenvolvimento de autonomia, criticidade e reflexividade no exercício da profissão. Além dessas questões, trazemos neste tópico outros elementos que vêm corroborar, ainda mais, para a desvalorização e, consequentemente, para a periferização docente.

“A crise da educação no Brasil não é uma crise, é um projeto”. (Ribeiro, 1977). A frase que pode ter se tornado um jargão, continua fazendo sentido quase meio século depois de proferida. Diretamente associada à esta situação, encontra-se a produção de uma docência marginalizada como parte desse projeto político ${ }^{2}$ educacional de sucateamento da educação pública nacional.

A docência periférica é o termo que cunhamos neste trabalho para tratar do magistério que, a despeito da sua relevância social e da importância para o desenvolvimento da qualidade da educação, tem enfrentado crescente desprestígio. Discutiremos neste tópico, o fortalecimento da periferização da docência no panorama nacional, buscando identificar aspectos que corroboram ou podem vir a corroborar para mantê-la sob status de profissão de segunda ordem. Nesse sentido, levantamos alguns aspectos sobre a construção dessa depreciação do magistério no país e discutimos sobre determinados pontos no cenário político-educacional que vem fragilizar ainda mais as perspectivas de formação inicial e exercício para valorização e reconhecimento da profissão.

No Brasil, já há algum tempo, observam-se sinais e evidências de uma profunda crise da profissão docente. Porém, infelizmente, as respostas dos governantes brasileiros para tal situação têm sido, via de regra, insuficientes, equivocadas e ineficazes. (Diniz - Pereira, 2011, p.36).

\footnotetext{
${ }^{2} \mathrm{O}$ conceito de política adotado aqui baseia-se nesta concepção: “A política educacional diz respeito às decisões que o Poder Público, isto é, o Estado, toma em relação à educação". (SAVIANI, 2008, p.1)
} 
Uma breve revisita na história da educação permite um delineamento sobre a crise do magistério. Para os teóricos da área, ela se encontra diretamente ligada ao descaso do país para com a universalização e gratuidade da educação, sobretudo, em se tratando da educação básica. Para Aranha (1996), o ponto fulcral dos problemas educacionais no Brasil está fundamentado na busca pela manutenção histórica dos privilégios de classe, que cria uma dualidade educacional, gerando exclusão e segregação social.

Segundo a autora, é sob esse molde sociopolítico contraditório e desigual que o país inicia tardiamente o processo público de formação docente, na segunda metade do século XIX. Basta recobrar que é somente com a Lei de Diretrizes e Bases da Educação Nacional 9.394/1996 que se passa a exigir formação em licenciatura plena para atuar na educação básica. E, vinte e cinco anos depois de sua vigência, ainda se admite formação docente em nível médio para atuar na educação infantil e séries iniciais do ensino fundamental.

São inúmeros os aspectos históricos que poderiam ser apontados para ilustrar o descaso para com a formação de professores no país e sua estreita ligação com a pouca valorização da educação, especialmente a educação básica. O que sugere a ideia da existência de uma intencionalidade política de periferização do magistério como um projeto de empobrecimento da educação pública.

As análises sobre os números do INEP, revelam a pouca atratividade da profissão, levando-a a ocupar o lugar de plano secundário no processo de escolha dos jovens. Apenas 20,5\% dos estudantes que ingressam no nível superior entre 2017 e 2018 optam pelas Licenciaturas. Enquanto o bacharelado tem concentração de 58,0\%, e o tecnológico tem 20,9\% dos estudantes. (BRASIL, 2018, p.16).

[...] cada um de nós sabe que o que somos tem muito a ver com nossa origem familiar e de classe social. Com as possibilidades culturais. Por exemplo, as possibilidades ou não de estudo sem trabalho vivenciadas desde a educação fundamental têm uma força socializadora sobre as possibilidades e limites de escolhas profissionais. (Arroyo 2013, p.127).

Outra informação importante se refere ao perfil dos jovens que optam pelas licenciaturas. Segundo Gatti, até $2014,{ }^{3}$ 68,3\% dos jovens que concluíram a licenciatura eram oriundos exclusivamente da escola pública, fato que leva a autora a considerar que "tornaram-se cursos "populares", à medida que os seus alunos passaram a efetivamente representar as camadas majoritárias da população". (2019, p.147)

Além da baixa procura, as licenciaturas enfrentam elevadas taxas de evasão, resultado que a autora informa estar ligado à desvalorização da profissão e às dificuldades dos jovens das classes populares em conciliar estudos e atividades laborais durante a graduação. Questões que incidem diretamente sobre o déficit de professores na educação básica e sobre a dificuldade de consolidação de uma identidade docente, corroborando com o imaginário coletivo de "vocação e amor" como requisitos suficientes para o exercício do magistério.

Levando em consideração a história da educação e os dados apontados, compreendemos que a baixa preferência pelo magistério como carreira profissional está amparada tanto na realidade objetiva quanto na realidade subjetiva. Portanto, o imaginário social que se constrói sobre a docência diz muito sobre as condições estruturais implicadas no exercício do magistério que, de certa forma, define quem entra e quem não entra na profissão.

\footnotetext{
${ }^{3}$ Gatti ( 2019), informa que o ano de 2014 não entrou na conta do ENADE.
} 
No que diz respeito às perspectivas de formação e exercício para valorização e reconhecimento do magistério, as mais recentes alterações na política de formação de professores são desalentadoras. Destacamos alguns aspectos que possivelmente vem contribuir para a desvalorização profissional e para a periferização da docência. A saber, as últimas alterações na LDB 9.394/1996 provenientes da Lei 13.1415/2017; Resolução CNE/CP 02/2019 que institui a Base Nacional Comum para Formação Inicial de Professores da Educação Básica -BNC- formação. É preciso alertar que não se propõe aqui esgotar tais documentos, mas apontar quais aspectos se consideram mais preocupantes para a pauta em questão.

À reforma do ensino médio, implementada pela Lei 13.415/2017, caberiam incontáveis críticas pela sua natureza segregacionista, excludente e reforçadora de desigualdades sociais. No entanto, focaremos no que atinge sobremaneira a formação e o exercício docente. O notório saber, por exemplo, ressurge, resgatando a figura do professor leigo. Ainda que a lei aponte a alternativa unicamente para a formação técnica profissional, suspeitamos que essa deva ser uma brecha perigosa para toda a educação. Sem falar que a proposta está em desacordo com as metas 15 e 16 do Plano Nacional de Educação do decênio 2014/2024, que preveem, respectivamente, que no interstício de 10 anos, todo professor obtenha o título na licenciatura da área em que atuam e que 50\% deles obtenham formação pós-graduada durante a vigência do plano.

Nessa perspectiva de esvaziamento da formação, a partir da supervalorização da prática em detrimento da teoria, encontram-se as bases sobre as quais se sustentam a prática histórica da admissão dos leigos na educação, já denunciado por Saviani (2013). Sobre essa assertiva, a afirmação, "Não é de hoje que enfrentamos dificuldades em ter professores habilitados para cobrir as demandas da população escolarizável [...] É um dos traços persistentes e problemáticos em nossa história". (Gatti, 2019, p.20).

Reconhecemos que a admissão de professores leigos é um problema antigo na história da educação nacional. A retomada legal dos professores leigos vem sinalizar maior retrocesso e descaso para com a formação de professores. O notório saber vem contrapor a importância dos saberes específicos da docência, quando considera que o domínio de um campo de conhecimento é suficiente para estar à frente de uma sala de aula. Desconsiderando, portanto, a necessidade do conhecimento sobre as teorias e práticas da educação, além de retomar um problema complexo que levamos séculos para superar.

Vale considerar, ainda, que o país apresenta números significativos de professores da educação básica sem a habilitação específica para o componente curricular em que atuam ${ }^{4}$. O notório saber surge, portanto, como mais uma ação política educacional que afronta a profissionalização do magistério, mas infelizmente não é a única. A BNC-Formação, aprovada através da Resolução CNE/CP 02/2019 e Resolução CNE/CP 01/2020, que regulam atualmente a formação de professores, por sua vez, também minimizam as lutas implementadas pela categoria docente e pela comunidade científica.

A contraposição ao professor leigo pressupõe a ampla defesa dos processos de formação docente. É preciso salientar, contudo, que a ênfase dada sobre a importância da formação inicial docente, não diz respeito apenas a um protocolo de acesso para a profissão. Para Tardif (2002); Libâneo, Oliveira e Toschi (2012) e Arroyo (2013), a formação de professores se faz importante também para fortalecer a identidade profissional, aprimorando saberes, práticas, reflexões, técnicas, discussões, análises, entre outros aspectos. Os pensadores defendem que esse processo formativo precisa estar alicerçado em uma concepção de práxis docente, onde o conhecimento e a reflexão profissional sobre o próprio fazer leva à modificação de práticas e construção de novos saberes.

Nesse sentido, de nada adianta garantir uma formação engessada, que cerceie a práxis docente, como se propõe na atual Base Nacional Comum para Formação Inicial de Professores da Educação Básica (BNC- formação). Este documento, criado como política de orientação para a formação dos professores da educação básica, adota as competências e habilidades da

\footnotetext{
4 “no Brasil, 37,8\% dos docentes não possuíam titulação em grau superior compatível com as disciplinas que lecionavam nos anos finais do Ensino Fundamental, em 2018". (BRASIL, 2019)
} 
BNCC como princípios basilares. Sua nítida adequação mercadológica desvirtua o caráter público da política educacional, enquanto aponta para esvaziamento de conteúdos e controle de práticas escolares.

Há no referido documento, evidências de uma lógica tecnicista/praticista para regular a formação de professores "A formação docente pressupõe o desenvolvimento, pelo licenciando, das competências gerais e específicas e as habilidades previstas na BNCC-Educação Básica" (Art. $2^{\circ}$ ). Como medida impositiva, o documento determina que os professores sejam formados para aplicar as habilidades e competências, o que vai na contramão da concepção multidimensional da docência e da formação crítica. Sem falar da invalidação da práxis docente, quando propõe colocar o professor como mero executor de ações pensadas e elaboradas por terceiros.

Tal concepção de formação, baseada na pedagogia das competências, tão fortemente defendida neste marco regulatório, amálgama uma visão restrita e instrumental de docência, em detrimento de uma concepção formativa que articula indissociavelmente a teoria e a prática, dentro de uma visão sócio-histórica, emancipadora e inclusiva. (Guedes, 2020, p.96)

Uma das justificativas utilizadas para a elaboração das mudanças na formação de professores, partiu da crítica sobre a excessiva carga teórica dos cursos de licenciatura, que segundo a BNCC, afasta os professores da realidade escolar. No entanto, fica evidente a ênfase dada a mecanização do processo formativo, que além de minimizar o campo teórico-conceitual, propõe práticas aligeiradas, a exemplo da formação pedagógica para professores não licenciados. A carga horária para esta formação foi reduzida ainda mais. Na Resolução 02/2015 estipulava-se entre 1.000 e 1.400 horas de efetivo trabalho acadêmico, já a Resolução 02/2019 estipula uma carga horária básica de 760 horas. Fica aqui o questionamento sobre o compromisso de uma política pública para formação de professores com a educação de qualidade quando reduz o que já não era satisfatório.

Para a Associação Nacional pela Formação do Profissionais da Educação- ANFOPE (2017) e para a Associação Nacional de Pós-Graduação e Pesquisa em Educação- ANPED (2018; 2019), o atual direcionamento para a política de formação de professores advém de uma intensa crise institucional e de atitudes antidemocráticas. Ressaltamos, contudo, a necessidade de considerarmos as bases sobre as quais se alicerçam o atual cenário educacional de retrocessos. Nesse sentido, encontram-se movimentos políticos conservadores que ocorrem não somente no Brasil, mas em nível mundial.

As críticas realizadas pelas entidades corroboram com o pensamento de Apple (2001) quando associam as atuais mudanças no cenário educacional a um projeto político-econômico internacional que vem crescendo e se institucionalizando. Esses movimentos de cunho neoliberal e neoconservador têm influenciado na reestruturação da educação, impondo mudanças sobre sistemas, currículos e formação de professores. Dessa forma, determina-se uma agenda de estratégias mercantilistas e mecanismos de controle sobre o conhecimento escolar. Além de promoverem uma reestruturação cultural, que romantiza a educação e negligencia os processos multiculturais e de inclusão social. Para o autor, existem grupos distintos à frente desse processo reestruturador, mas que mantém interesses em comum, a exemplo do controle dos processos educativos.

Este é o panorama sob o qual discutimos a compreensão da docência. Desde a opção pela carreira às perspectivas para o exercício profissional, abarcando análises sobre aspectos históricos e sobre as políticas educacionais.

A despeito dos estudantes da licenciatura denotarem conhecer as condições precárias da profissão, relatarem sobre os desafios impostos pelos processos sociais de desvalorização da docência e afirmarem ter medo e/ou preocupação com o atual cenário político do país, pouco associaram as falas às políticas educacionais propriamente ditas. Quando se referiram às perspectivas negativas sobre o magistério, os estudantes frequentemente relataram sobre a falta de incentivo do governo para a carreira. 
A desvalorização docente é o aspecto que mais sobressai durante os diálogos desta investigação, levando os entrevistados a se aproximar da construção identitária da profissão sobre as considerações de Arroyo, onde prevalece a cultura do magistério na luta por direitos e por reconhecimento social.

Ficou claro à sociedade e aos diversos grupos sociais que o magistério está identificado com a luta por direitos, pelo direito mais elementar de todo trabalhador ao reconhecimento do valor do trabalho, ao tratamento justo como educadores, ao valor da educação na sociedade, ao seu valor social como profissionais da educação. (Arroyo, 2013, p.191)

Acrescentamos, ainda, a pouca perspectiva de mudança que os licenciandos apresentam sobre o cenário político brasileiro, classificado como sendo desfavorável à valorização da carreira. Para caracterizar a questão, eles apontam os cortes sofridos nos investimentos direcionados à educação e a ausência de algum projeto político específico que proponha melhorar o cenário da profissão docente. Fato, que segundo os entrevistados, contribui para as baixas perspectivas que têm para o futuro profissional.

Outro aspecto que entrou como gerador de baixa expectativa sobre o magistério foi a afirmação frequente sobre a ausência de infraestrutura adequada nas instituições escolares e sobre o excesso de expectativa do êxito educacional sobre a função docente. Sobre esta última, pontuam a ausência da participação efetiva da família no processo educativo, sobrecarregando o magistério.

Corroborando com dilemas semelhantes levantados pelos entrevistados, Nóvoa considera que a ausência da sociedade no cumprimento de seus papéis educativos, tem trazido reflexos no cumprimento do dever escolar e tem gerado dilemas para o magistério "Simultaneamente, a demissão das famílias e das comunidades de suas funções educativas e culturais transferia uma multidão de missões para as escolas". (NÓVOA, 2017, p.220). Assim, defende a reconstrução da escola como espaço público da educação com modificações nas formas da escola e professores se relacionarem com a comunidade. Isso requer uma formação efetiva da dimensão política docente, valorizando trocas e partilhas, demandando outros saberes que muitas vezes não se reconhecem como legítimos à docência.

Essa dimensão política da docência como ponto de equilíbrio para com a sociedade, valorizada e requerida pelo autor é frágil na formação dos licenciandos. Em vários momentos da entrevista, os estudantes sinalizaram para uma docência impotente diante dos problemas do cotidiano escolar. Emergiu de forma mais intensa nas falas, os problemas sóciocomportamentais e metacognitivos dos estudantes como responsabilidade quase que exclusiva das famílias. Ficou perceptível que os estudantes encerram o magistério na dimensão técnica, cujo papel docente está restrito no desenvolvimento dos saberes disciplinares da matemática.

Quando solicitados a avaliarem o cenário político educacional do país e suas implicações para o magistério, alguns entrevistados sugeriram presença de perseguições ideológicas na atualidade. Um deles citou o movimento escola sem partido, juntamente com a proposta de militarização das escolas públicas como questões que geravam temor em relação ao futuro exercício da profissão, mas sem aprofundar o debate. Chamou atenção, inclusive, que um dos entrevistados do grupo dos veteranos pediu para não se pronunciar sobre o tema. Havia, claramente, em ambos os grupos, um clima de tensão e receio de se pronunciar "Falar de política hoje é um pouco complicado porque são pensamentos diferentes, cada um defende o que acha certo e quando você dá seu ponto de vista sobre o que acha certo, acaba ofendendo outras pessoas por discordar". (BRANCO, 2020)

Notamos uma relação conflituosa na dimensão política dos futuros professores, embora não se tenha percebido, nos entrevistados, uma consciência tão clara sobre a importância dela para o magistério. Quando concebem a docência como uma profissão desvalorizada, por exemplo, os licenciandos acreditam que as mudanças para a profissão dependem, quase que 
exclusivamente, de ações do Estado e das famílias. O professor, apesar de ser apontado como protagonista da educação, tem seu papel de sujeito histórico negligenciado nas falas dos estudantes. O único momento em que surge a questão sobre a possibilidade de participação e/ou mobilização docente em prol das transformações que vislumbram para a escola e para a educação, percebemos a latente contradição:

Eu acho que isso não deveria ser pensado pelo professor. A um tempo atrás eu li algo a respeito dos professores serem responsabilidade do governo federal, então eu acho que essa responsabilidade deveria ser do estado, porque se pararmos para pensar não vai dar em nada. Quantas vezes eu participei de manifestações de professores que reivindicavam tantas coisas e nunca foram ouvidos. O governo deveria pensar em priorizar a educação no país, não me refiro a "politicagem", me refiro a política correta, se priorizasse educar hoje não estaríamos tendo esta conversa. (Branco, 2020)

Quando foi proposta uma discussão nos grupos focais acerca da BNCC e da recente proposta de formação de professores, percebemos uma compreensão pouco aprofundada sobre o conteúdo do documento e sobre sua influência no futuro exercício profissional. Eles indicaram que tiveram algum contato com a BNCC, mas somente um dos licenciandos citou, ainda assim de forma genérica, uma relação com a reforma do ensino médio. Quanto a BNC-Formação, relataram não ter qualquer ciência sobre as implicações para a profissão. "Já ouvi falar, mas eu não pesquisei sobre e, não tenho nenhum embasamento teórico. (Lilás, 2020)

Essa questão vem corroborar para uma reflexão sobre possível lacuna na formação inicial dos licenciandos. Decorre daí um questionamento, como estão sendo discutidas institucionalmente as alterações propostas para a formação inicial e continuada de professores da educação básica dentro das licenciaturas? Não se pretende respondê-la. Fica, portanto, o questionamento para futuras investigações.

Outros dilemas apontados para o exercício docente dizem respeito aos ciclos escolares e à violência escolar. Para os licenciandos, a aprovação automática no final dos ciclos escolares são, em grande parte, o motivo para o descaso dos alunos para com a aprendizagem e a justificativa da pouca credibilidade que estes depositam sobre o papel do professor. "Então o aluno que tem a segurança de que não vai ser reprovado acaba não se dedicando para estudar. $\mathrm{O}$ sistema cobra muito do professor sem dar condições a ele”. (Azul, 2020). Quanto à violência, surge como fator de ameaça para permanência na carreira. Alguns entrevistados afirmam que precisam avaliar futuramente como ficará a realidade das escolas frente à violência, para então decidir se continuarão ou não em sala de aula.

Fica evidente, também, na fala dos estudantes uma supervalorização da prática na concepção e exercício da docência. Quando necessitam definir o magistério sempre se remetem às experiências com a escola, sejam elas na condição de aluno da educação básica, da licenciatura ou na figura do estagiário/docente. Mas onde se situa o verdadeiro problema dessa percepção?

Dentro dessa perspectiva, os entrevistados indicaram a formação inicial desenvolvida sobre um distanciamento entre saberes de formação e exercício profissional. No entanto, destacaram que foi durante a graduação que aprenderam sobre a importância do planejamento, transposição didática, metodologias e postura do professor em sala de aula. Quando se referiram ao distanciamento entre academia e chão de escola, alertaram para o fato de não se sentirem preparados para lidar com a falta de comprometimento dos estudantes e negligência das famílias para acompanhar a aprendizagem; conflitos comportamentais no ambiente da sala de aula; violência e presença de drogas ilícitas nas dependências escolares; ausência de materiais e estrutura precária dos prédios.

Essa constatação, inclusive, influenciou a concepção dos licenciando sobre o magistério após o contato com a graduação. Para eles, ficou evidente na licenciatura que a responsabilidade dos professores é maior do que supunham anteriormente. Algumas vezes ficou nítido nos grupos focais, que as tensões apresentadas surgiram após o contato direto com a 
realidade da escola pública, seja nas situações de estágio ou de experiência com o Programa Institucional de Bolsas de Iniciação à Docência- PIBID.

Em Lessard e Tardif encontramos elementos suficientes para compreensão das falas apresentadas. É preciso discutir sobre o trabalho como uma atividade imprescindível, que permite realizar a mobilização e a construção dos saberes profissionais. "[...] a prática profissional nunca é um espaço de aplicação dos conhecimentos universitários. Ela é, na melhor das hipóteses, um processo de filtração que os dilui e os transforma em função das exigências do trabalho" (Lessard; Tardif, 2014, p.257). Dito isto, o autor considera a importância dos saberes experienciais para a formação docente, sem desconsiderar a formação inicial. Alertando, contudo, para a necessidade de maior compreensão e valorização dos saberes constituídos pela experiência.

Possivelmente, encontre-se neste conflito prática/teoria, a falta alertada pelos licenciandos. A formação inicial pode estar desconsiderando suas experiências em sala de aula e, consequentemente, deixando de promover uma formação alicerçada na epistemologia da prática, como defendida pelos autores.

A formação de um profissional capaz de refletir sobre sua experiência para compreender e melhorar o seu ensino, com base na epistemologia da prática, que se sustenta em três conceitos fundamentais: conhecimento na ação, reflexão na ação e reflexão sobre a reflexão na ação. Nessa perspectiva, valoriza-se a prática profissional como momento de construção do conhecimento por meio da reflexão e reconhecimento do conhecimento tácito, derivado das soluções dos problemas encontrados na prática cotidiana. (Gatti, 2019, p. 184-185 apud Schön 1995, p.91)

Os participantes da pesquisa sugeriram, inclusive, a possibilidade de incluir no currículo da licenciatura, um período que oportunizasse aos estudantes maior contato com as escolas e com os professores que atuam nelas, favorecendo maior coerência com a realidade da sala de aula. Possibilidade esta, inclusive, destacada por Lessard e Tardif (2014), quando mencionam a necessidade de desenvolver reflexões e pesquisas sobre a dinâmica concreta das escolas. Local onde os currículos, com todos os conflitos, dificuldades e possibilidades reais, são de fato desenvolvidos.

Os conflitos e contradições que se apresentaram na constituição docente dos jovens licenciandos em Matemática não são novas. Mesmo a questão político-ideológica que muito os preocupa e tensiona ainda mais suas perspectivas, já esteve presente em outro momento histórico do país. Fato que não minimiza a seriedade da questão, pelo contrário, são problemas que vêm sendo denunciados, debatidos e teorizados ao longo de muitas décadas. No entanto, a crise na educação parece encrustada na realidade brasileira, na qual a marginalização do magistério entra, ao mesmo tempo, como causa e consequência.

\section{Considerações Finais}

A crise do magistério faz parte de um processo histórico nacional que demonstra uma intencionalidade tácita de sucateamento e esvaziamento da educação pública escolar. Não se pode, contudo, negligenciar o pano de fundo que sustenta as últimas políticas traçadas para a formação de professores no país, nas quais é perceptível retrocessos e medidas que visam menos valorizar a carreira do magistério do que atender aos interesses de grupos hegemônicos. Neste cenário, desenvolve-se uma política de formação de professores fragmentada, enquanto os documentos oficiais colocam os profissionais docentes como únicos responsáveis pelo sucesso ou fracasso da educação, condicionando a formação inicial e continuada de professores aos mecanismos do neotecnicismo vigente.

A despeito de muitas investigações existentes apontarem que a escolha pela profissão ocorre como opção possível para os jovens das classes trabalhadoras, neste trabalho quase a totalidade dos estudantes indicam ter escolhido a Licenciatura em Matemática por identificação com a profissão. Não foge à regra, todavia, o fato de serem estudantes e trabalhadores, questão que por si só já define condições complexas para a construção da identidade profissional do magistério. A difícil rotina de 
conciliar trabalho e estudos desses jovens deve ser considerada como um indicador negativo para se pensar a formação de professores, fazendo-se necessária a criação de políticas atraentes de permanência nas licenciaturas. Sobretudo no que diz respeito as bolsas de incentivo. Estas precisam compensar a necessidade que os jovens têm de sustentar suas famílias, caso contrário será muito difícil renunciar seus trabalhos remunerados, ainda que sejam precários e de carga horária extenuante, como registramos nas entrevistas realizadas.

Como pensar uma formação inicial de qualidade para o magistério quando temos um coletivo de estudantes que mal tem tempo para organizar uma rotina de estudos? Os entrevistados sinalizaram muitas dificuldades em cumprir com os horários de aulas na graduação, muitos deles contam com a compreensão dos professores para abonar os atrasos. Como só podem estar presentes no turno noturno, não conseguem participar das atividades culturais e/ou extracurriculares da instituição. Situação essa que coaduna com as considerações de Arroyo (2013) acerca das dificuldades enfrentadas pelas juventudes trabalhadoras nos cursos de graduação.

Ainda quanto à opção desses jovens de classes populares pelas licenciaturas, é necessária cautela ao abordar sobre a predileção deles por tais cursos, a fim de não incorrer no mesmo equívoco registrado no Texto Referência da BNCC, que em um silogismo infeliz reduz as escolhas pelos cursos de licenciatura associadas à menor capacidade cognitiva desses estudantes. Não se atenta o texto para os enfrentamentos realizados por esses jovens, construindo uma retórica perigosa sobre a competência cultural alienada das questões socioeconômicas.

É perceptível o reconhecimento dos estudantes sobre o processo de desvalorização do magistério, entretanto, evidenciamos fragilidades nas falas, no que tange uma consciência política ampliada. Para os futuros professores, a mudança para a educação depende somente do Estado. Com isso, eles negligenciam a dimensão política da docência e colocam os professores em um papel histórico secundário, fruto de uma relação determinista de sociedade.

Surgem nos resultados uma figura docente construída sobre os alicerces do praticismo. Os relatos sobre a concepção do magistério apontam, exclusivamente, para o campo da ação de ministrar aulas nas escolas. É evidente que os saberes experienciais têm muita importância no processo formativo. Entretanto, estes apontam para a importância da práxis docente, enquanto os licenciandos demonstram vagas referências acerca dos saberes específicos do magistério. Encontram dificuldades, inclusive, para nomear alguns poucos saberes apropriados durante a graduação. No máximo, apontam para aprendizagens acerca de comportamentos, posturas e técnicas de aulas.

Após análises dos dados, é possível perceber que o sentido atribuído pelos estudantes para a formação inicial está mais voltado para questões metodológicas, comportamentais e de desenvolvimento pessoal. Questões estas que podem estar mais associadas à garantia da obtenção de um título, que propriamente para uma formação intelectual e crítico-reflexiva da profissão. A necessidade de sobrevivência desses jovens faz com que os saberes acadêmicos sejam mais um consumo cultural, que legitimam a obtenção de uma vaga no mercado de trabalho, mas que minimizam o sentido de transformação da educação e das práticas escolares.

As tensões e contradições que surgem na construção da identidade docente não se revelam novas. A crítica realizada ao distanciamento da formação acadêmica em relação a realidade escolar; a aprovação automática dos estudantes da educação básica como uma perda de autonomia de exercício profissional; a violência presente no cotidiano das escolas, figuram como pontos principais de conflito durante os grupos focais.

Há uma contradição aparente na constituição docente desses jovens, ao mesmo tempo que demonstram muita angústia com a possibilidade de institucionalização de práticas severas de fiscalização e controle docente, relatam ainda nutrir esperanças de mudanças positivas no cenário profissional. Esta esperança, todavia, não se fundamenta em aspectos objetivos, mas no desejo mágico por dias melhores. 
Alertamos para o perigo da crise histórica da profissão, como parte de um projeto amplo de patrulhamento e desqualificação da educação pública, continuar perpetuando a falácia da responsabilidade individual dos professores sobre o fracasso da educação pública. Para tanto, faz-se urgente a revogação das resoluções CNE/CP 02/2019 e 01/2020 e a construção de uma proposta de formação inicial de professores que esteja voltada para a realidade dos jovens estudantes trabalhadores. Ou, simplesmente, continuará em curso a periferização do magistério como elemento do processo de mascaramento da realidade educacional.

Nesse sentido, alertamos para possibilidades de desdobramentos desta investigação, destacando a periferização do magistério, sobretudo sob a ótica da atual BNCC e BNC-formação, na atuação dos futuros professores da educação básica.

\section{Agradecimentos}

À instituição FAPESB, responsável pelo fomento da pesquisa e aos alunos participantes da instituição investigada, que acolheram e se disponibilizaram para participar dos grupos focais.

\section{Referências}

Anfope. (2017). Carta de Brasília. V Audiência Pública CNE de 11 de Set. de 2017. http://www.anfope.org.br/wp-content/uploads/2018/05/CARTA-deBrasilia_ANFOPE-V-Audiencia-Publica-CNE.-11.9.2017.pdf.

Anped. (2019). Contra a descaracterização da Formação de Professores: Nota das entidades nacionais em defesa da Res. 02/2015. anped.org.br/News/contra-descaracterizacao-da-formacao-de-professores-nota-das-entidades-nacionais-em-defesa-da.

Anped. (2021). Uma formação formatada. Posição da ANPED sobre texto referência- DCN e BNCC para formação inicial e continuada de Professores da Educação Básica. https://anped.org.br/news/posicao-da-anped-sobre-texto-referencia-dcn-e-bncc-para-formacao-inicial-e-continuada-de.

Apple, M. W. (2011). Reestruturação educativa e curricular e as agendas neoliberal e neoconservadora: entrevista com Michel Apple. Currículo sem Fronteiras, 1( 1), 5- 33 .

Aranha, M. L. A. (1996) História da Educação. (2 ed.). São Paulo: Moderna.

Arroyo, M. (2013). Ofício de mestre: imagens e auto-imagens. Petrópolis-RJ: VOZES.

Bardin, L. (1995). Análise de conteúdo. Lisboa: Edições 70.

Charlot. B. (2013). Da relação com o saber às práticas educativas. (1 ed.). São Paulo: Cortez.

Diniz - PEreira, J. (2011). O ovo ou a galinha: a crise da profissão docente e a aparente falta de perspectiva para a educação brasileira. Revista Brasileira de Estudos Pedagógicos. $92 \quad$ (230), 34-51. http://rbep.inep.gov.br/ojs3/index.php/rbep/article/view/2919/2654. https://doi.org/10.24109/21766681.rbep.92i 230.541

Ferreira, L., Santos, T. S. dos., Pedroso, S. (2020). Os egressos de um curso de licenciatura em matemática de uma universidade pública do estado do ParanáBrasil: potencialmente atuante ou potencialmente inativo, 9 (10). https://rsdjournal.org/index.php/rsd/article/view/9413.https://doi.org/10.33448/rsdv9i10.9413.

Flick, U. Introdução à pesquisa qualitativa. (2009). Porto Alegre: Artmed.

Gatti, B. A. (2012). Grupo focal na pesquisa em ciências sociais e humanas. Brasília: Liber Livro Editora.

Gatti, B. A. (Org.). (2019). Professores do Brasil: novos cenários de formação. Brasília: UNESCO.

Guedes. M Q. (2021). Política de formação docente: as novas diretrizes e a base nacional comum instituídas. Revista de ciências Humanas e Sociais. 1 (1), 82103. https://revistas.ufob.edu.br/index.php/revistasul-sul/article/view/658.

Instituto nacional de estudos e pesquisas educacionais anísio teixeira. (2020) Resumo Técnico: Censo da Educação Superior. http://download.inep.gov.br/educacao_superior/censo_superior/documentos/2019/censo_da_educacao_superior_2018-notas_estatisticas.pdf>..

Lei 9.394, de 20 de dezembro de 1996. Estabelece as diretrizes e bases da educação nacional. http://www.planalto.gov.br/ccivil_03/leis/19394.htm.

Lei 13.415, de 16 de fevereiro de 2017. Institui a Política de Fomento à Implementação de Escolas de Ensino Médio em Tempo Integral. Recuperado de: http://www.planalto.gov.br/ccivil_03/_Ato2015-2018/2017/Lei/L13415.htm.

Lei 13.005/2014, de 25 de junho de 2014. Aprova o Plano Nacional de Educação - PNE e dá outras providências. http://pne.mec.gov.br/18-planossubnacionais-de-educacao/543-plano-nacional-de-educacao-lei-n-13-005-2014.

Libâneo, J. C., Oliveira, J.F., Toschi, M, S. (2012). Educação escolar: Políticas, estrutura e organização. (10 ed.). São Paulo: Cortez. 
Research, Society and Development, v. 10, n. 10, e584101019282, 2021

(CC BY 4.0) | ISSN 2525-3409 | DOI: http://dx.doi.org/10.33448/rsd-v10i10.19282

Ludke, M., André, M. (2013) Pesquisa em educação: Abordagens qualitativas. (2 ed.) Rio de Janeiro: EPU.

Nóvoa, A. (2014). Os professores e o "novo" espaço público da educação. In: TARDIF, M., LESSARD, C. O ofício de professor: História, perspectiva e desafios profissionais. Petrópolis-RJ: Vozes.

Resolução $C N E / C P n^{o}$ 2/2015, de 1 de julho de 2015. Define as Diretrizes Curriculares Nacionais para a formação inicial em nível superior e para a formação continuada. http://portal.mec.gov.br/docman/agosto-2017-pdf/70431-res-cne-cp-002-03072015-pdf/file.

Resolução CNE/CP n 2/2019, de 7 de novembro de 2019. Define as Diretrizes Curriculares Nacionais para a Formação Inicial de Professores para a Educação Básica e institui a Base Nacional Comum para a Formação Inicial de Professores da Educação Básica (BNC-Formação). http://portal.mec.gov.br/index.php?option= com_docman \& view= download \& alias=135951-rcp002-19 \& category_slug=dezembro-2019-pdf \& Itemid=30192.

Ribeiro, D. (1977). Sobre o óbvio. Palestra na $29^{\circ}$ Reunião da SBPC. São Paulo.

Rocha, P. C. da S., Jucá, S. C. S., Silva, S. A. Monteiro, A. de O. (2019). Pesquisa qualitativa em Educação no Brasil: consolidação e desenvolvimento. Research, Society and Development, 8 (6). https://doi.10.33448/rsd-v8i6.1082.

Saviani, D. Política educacional brasileira: limites e perspectivas. (2008). Revista de Educação PUC-Campinas, (24), 7-16.

Tardif, M., Lessard, C. (2014) O ofício de professor: História, perspectiva e desafios profissionais. Petrópolis-RJ: Vozes.

Todos pela educação. (2019) Anuário Brasileiro da Educação Básica. São Paulo: Moderna. https://www.todospelaeducacao.org.br/_uploads/_posts/302.pdf.

Veiga, I. P. A., Araújo, J. C. S., Kapuziniak, C. (2017). Docência: Uma construção ético-profissional. São Paulo: Papirus. 